\title{
Serum cytokine and growth factor levels in patients with endometriosis
}

\author{
AYCURUK KUBATOVA ${ }^{1}$, AHMET ERDEM ${ }^{1}$, MEHMET ERDEM ${ }^{1}$, MEHMET FIRATMUTLU ${ }^{2}$, \\ UMIT KORUCUOGLU ${ }^{3}$
}

${ }^{1}$ Department of Obstetrics \& Gynaecology, Gazi University School of Medicine, Ankara, Turkey

${ }^{2}$ Department of Obstetrics \& Gynaecology, HRS Women Hospital, Ankara, Turkey

${ }^{3}$ Department of Obstetrics \& Gynaecology, Koru Hospital, Ankara, Turkey

\begin{abstract}
The aim of this prospective study is to define markers that can be used in the diagnosis and follow-up of patients with endometriosis by determining serum CA 125, transforming growth factor $\beta 1$ (TGF- $\beta 1)$, interleukin 6 (IL-6), and IL-12 levels. The study group consisted of 14 patients diagnosed to have mild to moderate peritoneal endometriosis, 47 patients with ovarian endometrioma during laparoscopy and 12 healthy patients as a control group. Serum CA 125, TGF- $\beta 1, I L-6$, and IL-12 levels were evaluated using ELISA kits. Serum CA 125 levels were significantly higher in the endometrioma group when compared to the control group $(p<0.001)$ and mild to moderate peritoneal endometriosis group $(p<0.001)$. Mean serum TGF- $\beta 1$ levels were significantly higher in the endometrioma group when compared to the mild to moderate peritoneal endometriosis group $(p<0.001)$. In addition, serum TGF- $\beta 1$ levels were found to be significantly different with regard to the stage of the endometriosis. Serum IL-6 levels were significantly higher in the endometrioma group compared to the endometriosis group $(p=0.024)$ and control group $(p=0.05)$. Mean serum IL-12 levels were lower in patients with endometriosis. In conclusion; TGF- $\beta 1$ and IL-6 measurements might be a promising alternative in adjunct to CA 125 for the non-invasive diagnosis of endometrioma. However CA 125, TGF- $\beta 1, I L-6$ and IL-12 seem not to have the diagnostic value in the diagnosis of early stage endometriosis. Of all the serum markers studied, only TGF- $\beta 1$ was found to be correlated with the stage of endometriosis.
\end{abstract}

Key words: endometriosis, serum marker, CA 125, TGF- $\beta 1$, IL-6, and IL-12.

(Centr Eur J Immunol 2013; 38 (4): 500-504)

\section{Introduction}

Endometriosis is an oestrogen-dependent clinical entity characterized by the presence of endometrial glands and stroma outside the uterus. It is estimated to occur in 3-10\% of reproductive age women [1-3]. Endometriosis interferes with the quality of life by causing dysmenorrhoea, dyspareunia, chronic pelvic pain and infertility.

Up to now, several mechanisms such as ectopic transplantation of endometrial tissue, coelomic metaplasia, induction theory and loss of apoptosis have been proposed to explain the etiopathogenesis of endometriosis. The immune system has been thought to play a role in the complex events of endometriosis secondary to the fact that retrograde menstruation was a common event in women, but not all women who had retrograde menstruation developed endometriosis. It has been hypothesized that the disease might develop as a result of altered immunologic clearance of viable endometrial cells [4]. Substantial evidence suggested that endometriosis was associated with a state of subclinical peritoneal inflammation, marked by increased inflammatory cytokines and growth factors. Cytokines and growth factors are soluble low-molecular-weight proteins with autocrine and paracrine effects that play a role in mitosis, angiogenesis and chemotaxis [5, 6].

The gold standard in the diagnosis of endometriosis is the histological examination of the surgically removed tissue. A serum marker that is equally valuable for the diagnosis of endometriosis has long been researched to prevent any invasive procedure for the accurate diagnosis. The most widely used serum marker for this purpose is CA $125[7,8]$. Several studies have been performed to detect

Correspondence: Mehmet Firat Mutlu, MD, Department of Obstetrics \& Gynaecology, HRS Women Hospital, Güneş Sokak No. 14 Kavaklıdere Ankara, Turkey, tel. 53232577 90, e-mail: firatmutlu78@ hotmail.com 
a serum marker equally or more valuable in the diagnosis of endometriosis, but the results were conflicting [9-14]. Most of these data pointed to a possible use of interleukin 6 (IL-6) and transforming growth factor (TGF- $\beta 1$ ) as serum markers of endometriosis. Our prospective study aimed to determine serum CA 125 , TGF- $\beta 1$, IL-6, and IL-12 levels in patients with endometriosis. The study was expected to define new serum markers that can be used in the diagnosis and follow-up of patients with endometriosis.

\section{Material and methods}

\section{Study design}

This was a prospective study of 73 women referred to the gynaecology clinic of the Gazi University School of Medicine with a clinical or sonographic suspicion of endometriosis and endometrioma, who underwent laparoscopy. The control group consisted of 12 healthy patients who underwent laparoscopy for suspected endometriosis or tubal ligation and were confirmed to be free of endometriosis and any ovarian cysts during surgery. The patients were at the age of 18-40 years. The approval of the ethics committee of the Gazi University and informed consent from all participants were obtained prior to the study.

The clinical suspicion of endometriosis was made according to the symptoms of dysmenorrhoea, chronic pelvic pain, dyspareunia, infertility, urinary and rectal symptoms. The sonographic suspicion was made by the typical ultrasound characteristics, the presence of cystic ovarian masses with homogeneous low-level internal echoes, punctuate peripheral echogenic foci and thick cystic walls. Ovarian endometriomas were detected before surgery by transvaginal ultrasound and then confirmed by histological examination. All ovarian endometriomas were $\geq 3 \mathrm{~cm}$. No peritoneal implants or deeply infiltrating endometriosis were observed during laparoscopy in the ovarian endometrioma group. In all patients with stage 1-2 endometriosis, multiple biopsies were taken from suspected appearance of endometriosis and were confirmed by histological examination.

Patients were divided into three groups: women with stage 1-2 endometriosis confirmed by laparoscopy according to the revised "American Fertility Society Classification" American Society for Reproductive Medicine (1997) ( $n=14)$; women with unilateral or bilateral endometrioma and no history of previous ovarian surgery $(n=47)$ and the control group $(n=12)$. Also to eliminate the possible effect of basal sonographic cystic structures on the results, five patients from the control group and one patient from the endometriosis group were excluded from the study due to the presence of ovarian cysts.

Patients with myoma uteri, dermoid cysts, ovarian cystic structures $>3 \mathrm{~cm}$ other than endometrioma, pelvic inflammatory disease, any malignancy and current users of oral contraceptives, GnRH analogues, progestin, danazol or patients using any hormonal therapy, were excluded from the study. None of the patients had taken anti-inflammatory medications or had been diagnosed with an inflammation or infection in previous 6 months before the study.

Laparoscopic surgery was performed in the proliferative phase of the menstrual cycle by insertion of a 10 $\mathrm{mm}$ umbilical trocar and two ancillary trocars in the lower abdomen. All interventions were carried out by two experienced laparoscopists (AE, ME). The same protocol was used during the diagnostic phase of laparoscopy. This included an inspection of pelvic and peritoneal organs, peritoneal washings, staging of endometriosis. All patients with suspected endometriosis and endometrioma had a routine histological confirmation of the condition.

Prior to anaesthesia induction, $10 \mathrm{ml}$ of venous blood were drawn from each patient. Blood samples were centrifuged at $3000 \mathrm{rpm}$ for 15 minutes and stored at $-50^{\circ} \mathrm{C}$ until assay. Serum CA 125 levels were measured by chemiluminescence using IMMULITE 2000 hormone analyzer (Diagnostic Products Corporation, Los Angeles, CA, USA). Serum TGF- $\beta 1$, IL-6, and IL-12 levels were measured by using solid phase sandwich enzyme linked immunosorbent assay (ELISA) kits (Biosource International, California, USA). Intra- and inter-assay coefficients of variation were $<10 \%$ for all assays.

\section{Statistical analysis}

Results were expressed as mean \pm standard deviation. Kruskal Wallis univariate analysis was used to compare the means of serum CA 125 , TGF- $\beta 1$, IL- 6 and IL-12 levels between groups. Nonparametric Mann-Whitney $U$ test was used to compare the means of serum CA 125, TGF- $\beta 1$, IL-6, and IL-12 levels between two independent groups. SPSS for Windows version 10.0 was used for all statistical analysis; $p<0.05$ was set as the significance criterion.

\section{Results}

Baseline characteristics of patients are summarized in Table 1. One way Anova test revealed no significant difference between groups with respect to mean ages $(p=0.29)$. The preoperative ultrasonographic examination of patients revealed ovarian cysts in one patient of the peritoneal endometriosis group (6.7\%), in all of the patients of the endometrioma group and in 5 patients of the control group $(29.4 \%)$. These were excluded from the study.

Preoperative serum CA 125 , TGF- $\beta 1$, IL-6 and IL-12 levels in all three groups are shown in Table 2. Kruskal Wallis univariate analysis demonstrated that three groups were significantly different from each other with respect to serum CA 125 levels $(p=0.001)$. The Post Hoc Scheffe test failed to show any difference between pelvic endometriosis and control groups, but CA 125 levels were 
Table 1. Baseline characteristics of patients

\begin{tabular}{lccc}
\hline & $\begin{array}{c}\text { Pelvic endometriosis } \\
(\boldsymbol{n}=\mathbf{1 4})\end{array}$ & $\begin{array}{c}\text { Endometrioma } \\
(\boldsymbol{n}=\mathbf{4 7})\end{array}$ & $\begin{array}{c}\text { Control group } \\
(\boldsymbol{n}=\mathbf{1 2})\end{array}$ \\
\hline Mean age \pm SD & $30.6 \pm 5.3$ & $32.6 \pm 7.4$ & $31.6 \pm 7.2$ \\
\hline $\begin{array}{l}\text { Marital status } \\
\text { singlemarried/divorced }\end{array}$ & $1(7.1 \%)$ & $8(17 \%)$ & $4(33.3 \%)$ \\
\hline Chronic pelvic pain & $13(92.9 \%)$ & $39(83 \%)$ & $8(66.7 \%)$ \\
\hline Dysmenorrhoea & $5(35.7 \%)$ & $24(51.1 \%)$ & $2(16.7 \%)$ \\
\hline Dyspareunia & $8(57.1 \%)$ & $34(72.3 \%)$ & $2(16.7 \%)$ \\
\hline Infertility & $6(42.9 \%)$ & $16(34 \%)$ & - \\
\hline
\end{tabular}

Table 2. Preoperative serum CA 125, TGF- $\beta 1$, IL-6, and IL-12 levels in all three groups

\begin{tabular}{|c|c|c|c|c|}
\hline & $\begin{array}{l}\text { Pelvic endometriosis } \\
\qquad(n=14)\end{array}$ & $\begin{array}{l}\text { Endometrioma } \\
\quad(n=47)\end{array}$ & $\begin{array}{l}\text { Control group } \\
\quad(n=12)\end{array}$ & $p$ \\
\hline $\begin{array}{l}\text { CA } 125 \\
(\mathrm{U} / \mathrm{ml})\end{array}$ & $14.9 \pm 7.9$ & $75.3 \pm 110.8$ & $14.7 \pm 8.7$ & $<0.001$ \\
\hline $\begin{array}{l}\text { TGF- } \beta 1 \\
(\mathrm{pg} / \mathrm{ml})\end{array}$ & $11089 \pm 4981$ & $17849 \pm 6856$ & $14934 \pm 6734$ & 0.004 \\
\hline $\begin{array}{l}\text { IL-6 } \\
(\mathrm{pg} / \mathrm{ml})\end{array}$ & $57.1 \pm 123.5$ & $98.1 \pm 152.7$ & $44.6 \pm 72.8$ & 0.02 \\
\hline $\begin{array}{l}\mathrm{IL}-12 \\
(\mathrm{pg} / \mathrm{ml})\end{array}$ & $80.1 \pm 49.6$ & $76.5 \pm 32.1$ & $69.6 \pm 35.4$ & 0.74 \\
\hline
\end{tabular}

significantly higher in the endometrioma group than both the pelvic endometriosis group $(p<0.001)$ and control group $(p<0.001)$. Three groups were also different from each other with respect to serum TGF- $\beta 1$ levels $(p=0.004)$. The Post Hoc Scheffe test showed no difference between control and pelvic endometriosis groups $(p=0.17)$ and between control and endometrioma groups $(p=0.15)$. But the endometrioma group was significantly different from the pelvic endometriosis group with respect to serum TGF- $\beta 1$ levels $(p=0.001)$. Kruskal Wallis univariate analysis demonstrated that three groups were significantly different from each other with respect to serum IL-6 levels ( $p=0.02$ ). Serum IL-6 levels in the endometrioma group were significantly different from both the control group $(p=0.05)$ and endometriosis $(p=0.024)$. The three groups were similar to each other with respect to serum IL-12 levels.

None of the serum markers studied (TGF- $\beta 1$, IL-6, and IL-12) had a positive correlation with serum levels of CA 125 with respect to the diagnosis and follow-up of endometriosis. As a correlation of serum markers among themselves was studied, only a weak correlation between IL-6 and IL12 was detected $(r=-0.256 ; p=0.006)$. Of all the serum markers studied, only TGF- $\beta 1$ was found to be correlated with the stage of endometriosis $(r=-0.424 ; p=0.001)$.

The association of serum CA 125 levels with clinical findings is summarized in Table 3. In both pelvic endome- triosis and endometrioma groups, the serum CA 125 level was not found to be associated with any clinical finding. Similarly, in both pelvic endometriosis and endometrioma groups, serum TGF- $\beta 1$ and IL-6 levels were not found to be associated with any clinical finding. In the pelvic endometriosis group, the IL-12 level failed to show any correlation with any clinical finding.

\section{Discussion}

The immune system has been thought to play a role in the complex events of endometriosis. Most studies performed up to now focused on detection of cytokines and growth factors in the peritoneal fluid and endometriotic tissues. The only serum marker that proved to be of potential use for the diagnosis and follow-up of endometriosis has been CA 125. CA 125 has been correlated with the stage of endometriosis and its level has been found to increase with higher stages [7]. Our study similarly detected that CA 125 levels were significantly higher in the endometrioma group than both the pelvic endometriosis group $(p<0.001)$ and control group $(p=0.001)$. However, a single serum CA 125 level has been reported to have a quite low sensitivity for the diagnosis of endometriosis [8]. Our study supported this finding as all of the patients with mild disease and $32 \%$ of patients with advanced disease had serum CA 125 levels 
Table 3. Association of serum CA 125 levels with clinical findings

\begin{tabular}{lcccccc}
\hline & \multicolumn{3}{c}{ Pelvic endometrios } & \multicolumn{3}{c}{ Endometrioma } \\
\cline { 2 - 7 } & $\begin{array}{c}(-) \\
(\boldsymbol{n}=\mathbf{9})\end{array}$ & $\begin{array}{c}(+) \\
(\boldsymbol{n}=\mathbf{5})\end{array}$ & $\boldsymbol{p}$ & $\begin{array}{c}(-) \\
(\boldsymbol{n}=\mathbf{2 3})\end{array}$ & $\begin{array}{c}(+) \\
(\boldsymbol{n}=\mathbf{2 4})\end{array}$ & $\boldsymbol{p}$ \\
\hline Chronic pelvic pain & $12.7 \pm 5.3$ & $17.2 \pm 11.6$ & 0.46 & $55.4 \pm 35.1$ & $94.5 \pm 150.4$ & 0.68 \\
\hline Dysmenorrhoea & $12.4 \pm 6.3$ & $15.5 \pm 8.8$ & 0.48 & $59.3 \pm 40.9$ & $81.5 \pm 128.0$ & 0.53 \\
\hline Dyspareunia & $13.1 \pm 5.8$ & $16.3 \pm 9.8$ & 0.56 & $49.7 \pm 37.2$ & $82.2 \pm 106.0$ & 0.41 \\
\hline Infertility & $16.4 \pm 4.0$ & $14.5 \pm 8.4$ & 0.58 & $64.3 \pm 81.3$ & $55.8 \pm 48.4$ & 0.87 \\
\hline
\end{tabular}

below $35 \mathrm{U} / \mathrm{ml}$, which is considered as a normal upper limit. As a consequence, the serum CA 125 level is inadequate for the diagnosis and follow-up of endometriosis patients and new serum markers with a high sensitivity and specificity would prove useful.

Cytokines and growth factors secreted from peritoneal surface cells or from endometriotic tissues are known to be crucial for the development of ectopic endometrial cells. This is the reason why this study included serum TGF- $\beta 1$, IL-6, and IL-12 levels. The TGF- $\beta 1$ secreted from ectopic endometrial cells is thought to play the major role in the pathogenesis of endometriosis by increasing adhesion of endometrial stromal cells to peritoneum, suppressing local immune response and protecting ectopic endometrial cells from clearing.

Transforming growth factor $\beta 1$ expressions by eutopic and ectopic endometrial tissues have been studied immunohistochemically $[15,16]$. Up to date there have been two published studies in the literature regarding the association of TGF- $\beta 1$ with endometriosis [16, 17]. Pizzo et al. found a significantly higher level of TGF- $\beta 1$ in both peritoneal fluid and serum of patients with endometriosis as compared to the control group in the study investigating the serum TGF- $\beta 1$ levels in patients with endometriosis [16]. The same study showed that peritoneal fluid and serum TGF- $\beta 1$ levels increased with the increased stage of endometriosis. In contrast, D'Hooghe et al. did not observe any significant difference in peripheral blood cytokine levels between deep infiltrating endometriosis compared to superficial disease [17]. In our study, the endometrioma group was significantly different from the pelvic endometriosis group with respect to the serum TGF- $\beta 1$ levels $(p<0.001)$. In addition, the serum TGF- $\beta 1$ level was found to be the only serum marker correlated positively with the stage of endometriosis $(r=-0.424 ; p=0.001)$. Thus, the serum TGF- $\beta 1$ level might be considered as a valuable marker of endometriosis. But because of different assays, a lack of standard measurement is a significant obstacle.

Two proinflammatory cytokines thought to play a role in the etiopathogenesis of endometriosis are IL-6 and IL-12. Results of studies investigating peritoneal fluid and serum IL-6 levels in patients with endometriosis are conflicting $[5,11,18-20]$. Some studies report an increase in perito- neal fluid and serum IL-6 levels in patients with endometriosis and even a positive correlation with an increased stage of disease, however, some fail to prove this association. In some studies investigating serum IL-6 levels in patients with endometriosis, it has been reported that serum IL-6 levels were higher in patients with endometriosis as compared to the control group [9, 11, 12, 21, 22]. However, this correlation was not verified by other authors $[14,17,23-25]$. In a relatively recent study, serum IL-6 levels were increased in all women with endometriosis and in those with minimal-mild endometriosis, compared with controls [26]. The authors argued that the use of IL-6 as a serum marker for the diagnosis of endometriosis is useful. Our study demonstrated that serum IL-6 levels in the endometrioma group was significantly different from the control group $(p=0.05)$. Although the highest serum IL-6 level was detected in patients with stage 4 disease (156.3 \pm 263.3 ), three groups were not significantly different from each other. On the other hand, Martinez et al. revealed that IL-6 levels appear higher in patients with mild to moderate endometriosis, which is in contrast with our findings [21]. It is a well-established fact that the ovary is the major source of the peritoneal fluid. Therefore, patients with endometrioma may have higher concentrations of cytokines in the peritoneal fluid [27]. Consequently, this may explain why IL-6 levels were higher in the endometrioma group in comparison to patients with an early stage endometriosis in our study.

Differences that are mentioned in the studies may be a result of several factors, such as differences in control groups, differences in compared pathologies (i.e. ovarian cysts), differences in assay sensitivities and differences in the inclusion criteria of studies. Our study demonstrated that serum IL-6 levels increased especially in advanced stages of endometriosis. Previous findings showing that serum IL-6 levels decrease after use of GnRH analogues and after laparoscopic treatment render IL-6 a valuable marker for follow-up of patients with endometriosis [12].

Interleukin 12 is required for clearance of ectopic endometrial cells. Its decreased levels may be associated with defective clearing of ectopic endometrial cells shed to the abdominal cavity via retrograde menstruation or formed via metaplasia. In their endometriosis model, Somigliana 
et al. demonstrated that IL-12 application prevented implantation of ectopic endometrial cells [14]. Also, p40 subunit of IL-12 has been previously claimed to inhibit natural killer cell activity and predispose to the development of endometriosis. Similar to IL-6, studies researching IL-12 levels in endometriosis have conflicting results $[11,28,29]$. In the only study investigating serum IL-12 level in patients with endometriosis reported in the literature, authors claimed that serum IL-12 levels were not different in patients with endometriosis as compared to the control group [11]. Similarly, our study found that three groups were similar to each other with respect to serum IL-12 levels.

As a result, in comparison to CA125, serum TGF- $\beta 1$, IL-6 and IL12 levels may be not sufficient enough to detect early stages of endometriosis. However, TGF- $\beta 1$ and IL-6 measurements might be a promising alternative in adjunct to CA 125 for the non-invasive diagnosis of endometrioma. Of all the serum markers studied, only TGF- $\beta 1$ was found to be correlated with the stage of endometriosis. However, more prospective studies are required to further clarify these findings.

The authors declare no conflict of interest.

\section{References}

1. Missmer SA, Cramer DW (2003): The epidemiology of endometriosis. Obstet Gynecol Clin North Am 30: 1-19, vii.

2. D'Hooghe TM, Debrock S, Hill JA, Meuleman C (2003): Endometriosis and subfertility: is the relationship resolved? Semin Reprod Med 21: 243-254.

3. Giudice LC, Kao LC (2004): Endometriosis. Lancet 364: 1789-1799.

4. Dmowski WP, Steele RW, Baker GF (1981): Deficient cellular immunity in endometriosis. Am J Obstet Gynecol 141: 377-383.

5. Harada T, Yoshioka H, Yoshida S, et al. (1997): Increased interleukin-6 levels in peritoneal fluid of infertile patients with active endometriosis. Am J Obstet Gynecol 176: 593-597.

6. Seli E, Arici A (2003): Endometriosis: interaction of immune and endocrine systems. Semin Reprod Med 21: 135-144.

7. Barbieri RL, Niloff JM, Bast RC Jr, et al. (1986): Elevated serum concentrations of CA-125 in patients with advanced endometriosis. Fertil Steril 45: 630-634.

8. Mol BW, Bayram N, Lijmer JG, et al. (1998): The performance of CA-125 measurement in the detection of endometriosis: a meta-analysis. Fertil Steril 70: 1101-1108.

9. Pellicer A, Albert C, Mercader A, et al. (1998): The follicular and endocrine environment in women with endometriosis: local and systemic cytokine production. Fertil Steril 70: 425-431.

10. Fasciani A, D'Ambrogio G, Bocci G, et al. (2001): Vascular endothelial growth factor and interleukin-8 in ovarian cystic pathology. Fertil Steril 75: 1218-1221.

11. Bedaiwy MA, Falcone T, Sharma RK, et al. (2002): Prediction of endometriosis with serum and peritoneal fluid markers: a prospective controlled trial. Hum Reprod 17: 426-431.
12. Cheong YC, Shelton JB, Laird SM, et al. (2002): IL-1, IL-6 and TNF-alpha concentrations in the peritoneal fluid of women with pelvic adhesions. Hum Reprod 17: 69-75.

13. Gagné D, Pagé M, Robitaille G, et al. (2003): Levels of vascular endothelial growth factor (VEGF) in serum of patients with endometriosis. Hum Reprod 18: 1674-1680.

14. Somigliana E, Vigano P, Tirelli AS, et al. (2004): Use of the concomitant serum dosage of CA 125, CA 19-9 and interleukin-6 to detect the presence of endometriosis. Results from a series of reproductive age women undergoing laparoscopic surgery for benign gynaecological conditions. Hum Reprod 19: 1871-1876.

15. Oosterlynck DJ, Cornillie FJ, Waer M, et al. (1991): Women with endometriosis show a defect in natural killer activity resulting in a decreased cytotoxicity to autologous endometrium. Fertil Steril 56: 45-51.

16. Pizzo A, Salmeri FM, Ardita FV, et al. (2002): Behaviour of cytokine levels in serum and peritoneal fluid of women with endometriosis. Gynecol Obstet Invest 54: 82-87.

17. D'Hooghe TM, Xiao L, Hill JA (2001): Cytokine profiles in autologous peritoneal fluid and peripheral blood of women with deep and superficial endometriosis. Arch Gynecol Obstet 265: 40-44.

18. Koyama N, Matsuura K, Okamura H (1993): Cytokines in the peritoneal fluid of patients with endometriosis. Int J Gynaecol Obstet 43: 45-50.

19. Keenan JA, Chen TT, Chadwell NL, et al. (1994): Interferon-gamma (IFN-gamma) and interleukin-6 (IL-6) in peritoneal fluid and macrophage-conditioned media of women with endometriosis. Am J Reprod Immunol 32: 180-183.

20. Taylor RN, Ryan IP, Moore ES, et al. (1997): Angiogenesis and macrophage activation in endometriosis. Ann N Y Acad Sci 828: 194-207.

21. Martínez S, Garrido N, Coperias JL, et al. (2007): Serum interleukin-6 levels are elevated in women with minimal-mild endometriosis. Hum Reprod 22: 836-842.

22. Othman Eel-D, Hornung D, Salem HT, et al. (2008): Serum cytokines as biomarkers for nonsurgical prediction of endometriosis. Eur J Obstet Gynecol Reprod Biol 137: 240-246.

23. Kalu E, Sumar N, Giannopoulos T, et al. (2007): Cytokine profiles in serum and peritoneal fluid from infertile women with and without endometriosis. J Obstet Gynaecol Res 33: 490-495.

24. Jee BC, Suh CS, Kim SH, Moon SY (2008): Serum soluble CD163 and interleukin-6 levels in women with ovarian endometriomas. Gynecol Obstet Invest 66: 47-52.

25. Seeber B, Sammel MD, Fan X, et al. (2008): Panel of markers can accurately predict endometriosis in a subset of patients. Fertil Steril 89: 1073-1081.

26. Mihalyi A, Gevaert O, Kyama CM, et al. 2010. Non-invasive diagnosis of endometriosis based on a combined analysis of six plasma biomarkers. Hum Reprod 25: 654-664.

27. Carmona F, Chapron C, Martínez-Zamora MÁ, et al. (2012): Ovarian endometrioma but not deep infiltrating endometriosis is associated with increased serum levels of interleukin- 8 and interleukin-6. J Reprod Immunol 95: 80-86.

28. Gazvani R, Bates M, Vince G, et al. (2001): Concentration of interleukin-12 in the peritoneal fluid is not influenced by the presence of endometriosis, its stage or the phase of the menstrual cycle. Acta Obstet Gynecol Scand 80: 175-178.

29. Zeyneloglu HB, Senturk LM, Seli E, et al. (1998): The peritoneal fluid levels of interleukin-12 in women with endometriosis. Am J Reprod Immunol 39: 152-156. 